\title{
LEVANTAMENTO QUALI-QUANTITATIVO DE EQUIPAMENTOS E ESTRUTURA DE CINCO PRAÇAS NA CIDADE DE SÃO PAULO, SP
}

Kelly Chaves de Oliveira ${ }^{1}$

Ana Paula Nascimento Lamano-Ferreira ${ }^{2}$

Mauro Ruiz ${ }^{3}$

\begin{abstract}
RESUMO
O crescimento desordenado acarreta danos para a paisagem urbana, diminuindo sua porção de área verde e gerando problemas de diferentes ordens. O presente trabalho teve por objetivo realizar um levantamento quali-quantitativo de equipamentos e estruturas presentes em cinco praças do município de São Paulo, SP. As praças selecionadas foram: Praça Franklin Roosevelt, Praça Silvio Romero, Praça Novo Mundo, Praça Benedito Calixto e Praça Floriano Peixoto. Após esta seleção foi realizado o levantamento quali-quantitativo das praças por meio da aplicação de metodologia de avaliação e qualificação de praças desenvolvida por De Angelis et al. (2004). Observa-se que as praças avaliadas possuem equipamentos (bancos e lixeiras) e estruturas comuns (iluminação e segurança) e em alguns equipamentos e estruturas se diferenciam, o que auxilia a compreender como estes espaços são planejados pelos diferentes gestores públicos da cidade. A presença de vegetação também permite inferir que as praças visitadas em São Paulo possuem áreas verdes, entretanto não significa que a presença de recursos vegetais existentes seja a ideal para esses espaços públicos. Sugere-se estudos que possam levantar as expectativas dos frequentadores em relação à estrutura e equipamentos das praças, assim como levantamento do quanto a vegetação existente nas praças contribui e quanto pode contribuir com a cobertura vegetal, de modo que esses espaços públicos possam exercer funções ecológicas e também estéticas para o município.
\end{abstract}

PALAVRAS-CHAVE: Áreas Verdes, Administração Pública, Sustentabilidade.

\footnotetext{
${ }^{1}$ Turismóloga e Mestranda em Gestão Ambiental e Sustentabilidade, Universidade Nove de Julho UNINOVE. E-mail: kellychaves@gmail.com

${ }^{2}$ Profa. Dra. do Programa de Gestão Ambiental e Sustentabilidade da Universidade Nove de Julho UNINOVE. E-mail: apbnasci@yahoo.com.br

${ }^{3}$ Profa. Dra. do Programa de Gestão Ambiental e Sustentabilidade da Universidade Nove de Julho UNINOVE. E-mail: apbnasci@yahoo.com.br
} 


\section{INTRODUÇÃO}

Nos últimos anos a atenção dada aos espaços verdes urbanos vem crescendo gerando diversos estudos e projetos sobre o tema. A importância destes espaços está relacionada à conservação da biodiversidade e à melhoria da qualidade de vida humana (BARBOSA et al., 2007; GODDARD et al., 2009; SUSHINSKY et al., 2013).

O crescimento desordenado acarreta danos para a paisagem urbana, diminuindo sua porção de área verde e gerando problemas de ordem econômica, política e sociocultural (LOBODA; ANGELIS, 2005; COPORUSSO; MATIAS, 2008). Enchentes, aumento da poluição e da quantidade de parasitas são só alguns dos problemas desencadeados pela destruição das áreas verdes em grandes cidades, onde muitas vezes a degradação social e ambiental avançam juntas, especialmente no Brasil (ACSELRAD, 2013; MOMM-SCHULT et al., 2013).

Diante deste contexto, as áreas verdes passaram a ser valorizadas como alternativas a coibir o avanço destes problemas e de certa forma até revertê-los, melhorando a qualidade de vida ambiental e social (BARROS; VIRGILIO, 2003; MOMM-SCHULT et al., 2013). Há, entretanto, desafios enfrentados pelos órgãos públicos ao fazer a gestão destes espaços.

Para Benini e Martin (2011) as praças podem ter áreas permeáveis e com cobertura vegetal, trazendo benefícios de área verde urbana, como melhoria na qualidade de vida e do ar. Entretanto, Caporusso e Matias (2008) complementam que áreas verdes urbanas são “...espaço livre urbano composto, predominantemente, por solo permeável e vegetação arbórea e arbustiva, de acesso público ou não, e que exerçam minimamente as funções ecológicas, estéticas e de lazer". Esta definição enfatiza a predominância de vegetação e solo permeável e inclui claramente áreas públicas e privadas, algo que não é feito por Benini e Martin (2011). Por outro lado, Mendonça (2007) traz uma definição mais estrutural e urbanística da praça, como sendo "espaços públicos com função de convívio social, 
inseridos na malha urbana como elemento organizador da circulação e de amenização pública, com área equivalente à da quadra, geralmente contendo expressiva cobertura vegetal, mobiliário rústico, canteiros e bancos”.

Para que uma área verde exerça em sua totalidade os benefícios que pode gerar, uma questão importante é o envolvimento da popualçao com estes espaços. Para isso é importante criar opções de lazer diversificadas e interessantes o suficiente para satisfazer os anseios dos cidadãos, encorajando-os a permanecer e desfrutar destes espaços (HAQ, 2011). Este pode ser o grande desafio dos gestores urbanos, uma vez que estes podem encontrar diferentes anseios pelos diferentes grupos populacionais. Para o espaço público ser atrativo para a população é importante resgatar o lado emocional que pode existir em relação a esse ambiente e a possibilidade de se viver uma experiência interativa com este espaço, que vai além da visual encontrada em televisão e computador (THOMPSON, 2002; MENDONÇA, 2007).

Em São Paulo, como em outras grandes cidades, a gestão pública se depara com um problema que precede todos estes desafios: a falta de áreas verdes existentes e de espaço para a criação de novas, decorrente de uma gestão inadequada do espaço urbano em gestões anteriores (MOMM-SCHULT et al., 2013).

Em relação às praças, dificilmente se vê a preocupação de conhecer a opinião do cidadão em relação aquele espaço e integrar essa informação de forma prioritária nos projetos criados. Segundo De Angelis et al. (2004), o que se vê é a falta de critérios para a elaboração do projeto até a fase de implantação, não havendo estudos sobre as características do local, da população local, da melhor forma de inserção da praça na malha urbana. O mais comum é a adoção de projetos padrões, que são simplesmente replicados a cada nova praça (De Angelis et al., 2004). Isto explicaria a falta de interesse da população por estes espaços e a preferência, em grandes centros urbanos, por outras opções de lazer, como parques ou shopping centers (Gomes, 2008). Para continuar atraindo a população, a praça tem que se mostrar tão interativa, moderna e prática quanto o homem atual. Dessa forma, o presente trabalho teve por objetivo realizar um levantamento qualiquantitativo de equipamentos e estrutura de cinco praças do município de São Paulo, SP. 


\section{DESENVOLVIMENTO}

\section{Métodos}

Para este estudo, foi escolhida a cidade de São Paulo que possui área urbana com 1.521,101 $\mathrm{Km}^{2}$ de extensão territorial e 11.821 .876 habitantes (IBGE, 2013) destacando-se como a maior aglomeração urbana da América Latina.

Para a seleção das praças pesquisadas foi realizada uma busca da relação de praças existentes no município de São Paulo, a partir do projeto "Praças Digitais, que conta com uma lista das praças a serem atendidas com Wi-Fi Livre. A partir deste projeto foram selecionadas cinco praças de tamanhos semelhantes, uma de cada região do município. As praças selecionadas foram: Praça Franklin Roosevelt, Praça Silvio Romero, Praça Novo Mundo, Praça Benedito Calixto e Praça Floriano Peixoto.

Tabela 1. Praças do município de São Paulo selecionadas para o levantamento quali-quantitativo de equipamentos e estrutura.

\begin{tabular}{llllcc} 
Região & Distrito & Suprefeitura & Praça & M $^{2}$ & No usuários \\
\hline Centro & Consolação & Sé & Praça Franklin Roosevelt & 15.000 & 500 \\
Leste & Tatuaapé & Mooca & Praça Silvia Romero & 18.000 & 200 \\
Norte & Vila Maria & Vila Maria & Praça Novo Mundo & 13.000 & 200 \\
Oeste & Jardim paulista & Pinheiros & Praça Benedito Calixto & 15.000 & 500 \\
Sul & Santo Amaro & Santo Amaro & Praça Floriano Peixoto & - & 300 \\
\hline
\end{tabular}

Fonte: $\underline{\text { http://www.prefeitura.sp.gov.br/cidade/secretarias/upload/chamadas/120 pracas } 1375458668 . p d f}$

Após esta seleção foi realizada uma avaliação quali-quantitativa das praças por meio da aplicação de metodologia de avaliação e qualificação de praças desenvolvida por De Angelis et al. (2004). Foram utilizadas duas fichas de avaliação segundo essa metodologia, onde a ficha 1 é utilizada para a avaliação quantitativa, e faz a contagem dos elementos presentes na praça e, a ficha 2, é usada para a avaliação qualitativa, que qualifica estes elementos. Para este trabalho, porém, as fichas foram adaptadas. Nas fichas 1 e 2 foi adicionado o ítem parque canino e na ficha 2 foi inserido o ítem acessibilidade e a coluna qualificação.

Para a qualificação dos elementos encontrados na praça, foram utilizados conceitos criados por De Angelis et al. (2004), que listou os critérios a serem utilizados na avaliação afim de reduzir sua subjetividade. Estes critérios estão 


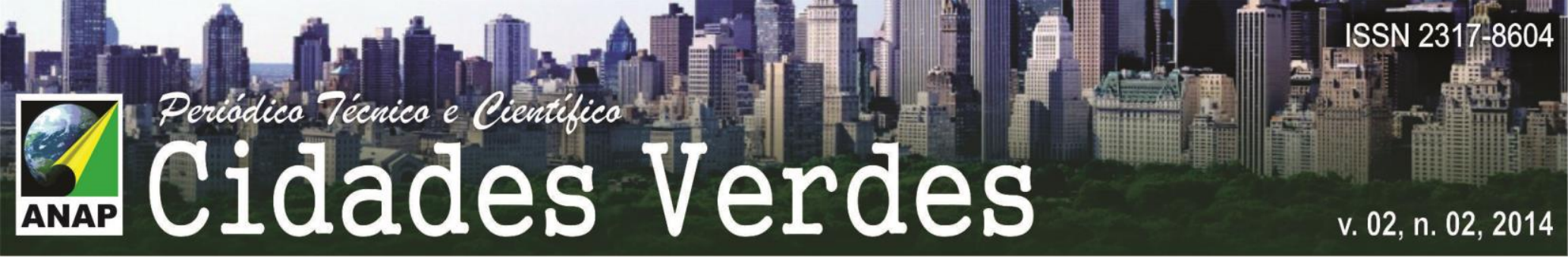

\section{Discussão}

Por terem um tamanho aproximadamente semelhante, a comparação das cinco praças estudadas permite verificar como cada espaço foi preenchido e quais elementos foram priorizados em sua gestão (Tabela 2). Pela sua análise notam-se diferenças de tipologias e quantidades de elementos encontrados nas cinco praças. A maior quantidade de bancos, sanitários e bebedouros nas praças Silvio Romero e F. Roosevelt, por exemplo, evidencia maiores cuidados em proporcionar mais bem estar aos usuários podendo levar a um tempo de permanência maior por parte dos frequentadores. A qualidade destes elementos também pode favorecer a permanência do visitante na praça. Neste sentido, a Praça Silvio Romero se destaca por ter mais bancos e com boa qualidade e mais opções de alimentação. A Praça Roosevelt, por sua vez, se destaca por ser a única a ter banheiro público.

As quantidades de iluminação e de bases de policiamento evidenciam a preocupação com a segurança de quem frequenta o local. Neste sentido, novamente as praças F. Roosevelt e Silvio Romero merecem destaque. No entanto, o policiamento da praça F. Roosevelt tem qualidade falha, uma vez que apesar de ter uma base da polícia civil, este espaço conta com frequentes usuários de drogas. A Praça Novo Mundo, mesmo não sendo tão iluminada, possui a maior e mais bem estruturada base policial dentre as demais, o que confere qualidade na segurança do local.

\begin{tabular}{|c|c|c|c|c|c|}
\hline EQUIPAMENTOS/ESTRUTURAS & $\begin{array}{c}\mathrm{N} . \\
\text { MUNDO }\end{array}$ & $\begin{array}{c}\text { S. } \\
\text { ROMERO }\end{array}$ & $\begin{array}{c}\text { B. } \\
\text { CALIXTO }\end{array}$ & $\begin{array}{c}\text { F. } \\
\text { ROOSEVELT }\end{array}$ & $\begin{array}{c}\text { F. } \\
\text { PEIXOTO }\end{array}$ \\
\hline 1. Bancos - material: madeira & 19 & 41 & 28 & 228 & 17 \\
\hline 2. Iluminação & 6 & 21 & 5 & 72 & 7 \\
\hline 3. Lixeiras & 16 & 23 & 6 & 41 & 18 \\
\hline 4. Sanitários & & & & 2 & \\
\hline 5. Telefone público & & & 1 & & 4 \\
\hline \multicolumn{6}{|l|}{ 6. Bebedouros } \\
\hline 7. Caminhos - material & 1 & 3 & 4 & 1 & \\
\hline 8. Palco/coreto & 1 & & & & 1 \\
\hline 9. Obra de arte / monumento & 1 & 2 & & 1 & 1 \\
\hline 10. Espelho d'água/chafariz & & & & & 1 \\
\hline 11 Estacionamento & 1 & & & 1 & \\
\hline 12. Ponto de ônibus & & 1 & & & \\
\hline 13. Ponto de táxi & & 1 & 1 & & 1 \\
\hline 15. Quadra esportiva & 2 & & 1 & & \\
\hline 16. Para prática de ex. físicos & 1 & & 1 & 1 & \\
\hline 17. Para terceira idade & 2 & & 3 & & \\
\hline 18. Parque infantil & 1 & & 1 & 1 & \\
\hline 19. Parque Canino & & & & 1 & \\
\hline
\end{tabular}




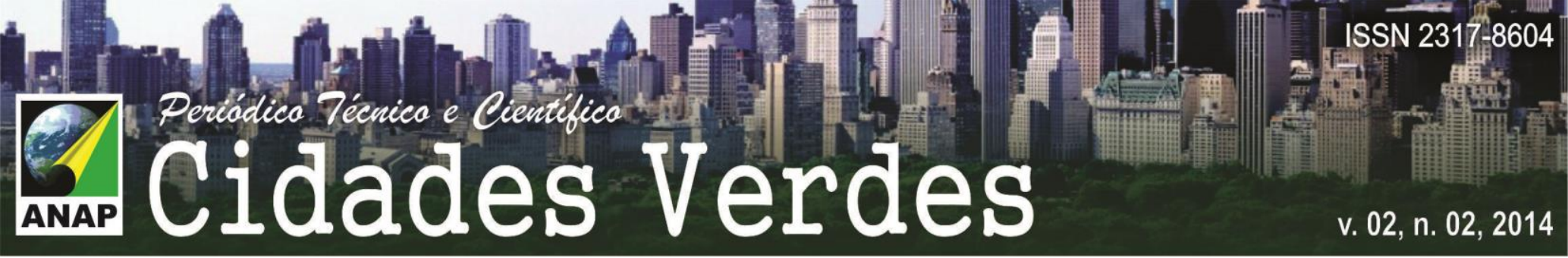

\begin{tabular}{lccccc}
\hline 20. Banca de revista & & 3 & 2 & & \\
21. Alimentação & 1 & 9 & 1 & & 4 \\
22. Identificação & 2 & 4 & 3 & 1 & 1 \\
23. Edificação institucional & 1 & 1 & 1 & 1 & 55 \\
24. Templo religioso & & 1 & 1 & 351 & 55 \\
TOTAL & 55 & 110 & 59 & \\
\hline
\end{tabular}

Fonte: Elaborado pelos autores

A existência de monumentos, espelho d'agua e paisagismo evidencia uma preocupação com a questão paisagística das praças. Esses elementos estão mais presentes nas praças Floriano Peixoto e Benedito Calixto. A praça Benedito Calixto, juntamente com a Praça Novo Mundo, se destacam por terem uma maior quantidade de elementos voltados para o esporte e lazer, como quadras, parque infantil e bicicletário.

Em relação ao conforto ambiental, todas têm uma cobertura vegetal ampla, com exceção da Roosevelt onde as árvores ainda são muito jovens não promovendo esse benefício ambiental. A acessibilidade também é boa em todas as praças, exceto na F. Peixoto, que é cercada e restringe a entrada da população em determinados dias e horários, o que pode desestimular a frequência dos usuários.

Para uma melhor gestão das áreas verdes urbanas na capital paulista, Momm-Schult et al. (2013) sugere que algumas medidas sejam priorizadas, como a integração de políticas urbanísticas e ambientais, priorização da infraestrutura verde, ampliação da regulamentação pública sobre a especulação imobiliária, criação de mecanismos que viabilizem projetos de longa duração e, por fim, (replanejamento e reestruturação do uso so solo - continuar com substantibos ao invés de verbos) repensar e reestruturar o uso do solo.

Tabela 3. Levantamento qualitativo dos equipamentos que compõem as praças estudadas.

\begin{tabular}{|c|c|c|c|c|c|}
\hline $\begin{array}{l}\text { ESTRUTURAS } \\
\text { AVALIADAS }\end{array}$ & N. MUNDO & S. ROMERO & B. CALIXTO & F. ROOSEVELT & F. PEIXOTO \\
\hline 01. Bancos & REGULAR & $\mathrm{BOM}$ & BOM & REGULAR & BOM \\
\hline 02. Iluminação alta & REGULAR & REGULAR & REGULAR & BOM & REGULAR \\
\hline 03. Iluminação baixa & & ÓTIMA & & & REGULAR \\
\hline 04. Lixeiras & BOM & ÓTIMA & BOM & BOM & $\mathrm{BOM}$ \\
\hline 05. Sanitários & & & & REGULAR & \\
\hline 06. Telefone público & & & REGULAR & & REGULAR \\
\hline 07. Bebedouros & & & & & \\
\hline 08. Piso & REGULAR & $\mathrm{BOM}$ & $\mathrm{BOM}$ & $\mathrm{BOM}$ & $\mathrm{BOM}$ \\
\hline $\begin{array}{l}\text { 09. Traçado dos } \\
\text { caminhos }\end{array}$ & $\mathrm{BOM}$ & $\mathrm{BOM}$ & $\mathrm{BOM}$ & RUIM & \\
\hline 10. Palco/coreto & RUIM & & & & BOM \\
\hline 11. Monumento & REGULAR & REGULAR & & $\mathrm{BOM}$ & BOM \\
\hline $\begin{array}{l}\text { 12. Espelho } \\
\text { d'água/chafariz }\end{array}$ & & & & & REGULAR \\
\hline 13. Estacionamento & PÉSSIMO & $\mathrm{BOM}$ & $\mathrm{BOM}$ & RUIM & \\
\hline
\end{tabular}


